\title{
SKIN CANCER INCIDENCE IN RENAL TRANSPLANT RECIPIENTS - A SINGLE CENTER STUDY
}

\author{
Lucie Kalinovaa,c*, Ondrej Majek ${ }^{b}$, Daniel Stehlik ${ }^{\mathrm{c}}$, Karel Krejci ${ }^{\mathrm{d}}$, Petr Bachleda ${ }^{\mathrm{a}}$
}

\author{
a $2^{\text {nd }}$ Department of Surgery, University Hospital Olomouc, Czech Republic \\ ${ }^{b}$ Institute of Biostatistics and Analyses, Masaryk University, Brno, Czech Republic \\ Department of Plastic and Reconstructive Surgery, University Hospital Olomouc \\ ${ }^{d} 3^{\text {rd }}$ Department of Internal Medicine, University Hospital Olomouc \\ E-mail: lucie.kalinova@email.cz
}

Received: July 20, 2010; Accepted: September 3, 2010

Key words: Cancer risk/Transplantation/Skin cancer/Immunosuppression

Aims. To provide the first single-center study of a Czech renal transplant program that compares skin cancer risk estimates to the general population.

Methods. We studied a total of 603 patients undergoing renal transplantation at the University Hospital Olomouc Transplant Center between January 1984 and December 2009. The mean time of follow-up was 5.5 years. Three patients were excluded for skin cancer diagnosis before transplant. The cohort was linked with the National Cancer Registry of the Czech Republic. For non-melanoma skin cancer (NMSC), the observed number of cancers were compared to the expected numbers of NMSC based on national cancer incidence rates stratified by age. The standartized incidence ratio (SIR) was calculated as observed-to-expected ratios.

Results. We found a total of 127 cases of skin cancers in 55 patients. 52/55 (94.5\%) were patients with non-melanoma skin cancers, $2 / 55$ (3.6\%) patients had malignant melanoma, and we uncovered one case of merkel cell carcinoma of the skin (1.8\%). There were no cases of Kaposi's sarcoma, cutaneous lymphoma or malignant fibrous histiocytoma. For NMSC, the overall SIR was 7.39 (95\% confidence interval 5.52-9.70). Thus, skin cancer was the most common malignant condition, representing $64.1 \%$ of all malignant tumours detected in study population.

Conclusion. We confirmed that skin cancer is a major complication in renal transplant recipients. Therefore it is important to increase the intensity of surveillence for these lesions in transplant patients.

\section{INTRODUCTION}

Renal transplantation is currently considered the therapeutic method of choice for end-stage renal failure in a selected group of patients. Adequate graft function however, requires lifelong immunosuppressive treatment and the resultant modification to the immune system is associated with increased risk of various cancers, particularly those involving viruses. Skin cancers are the most common malignant conditions in transplant recipients and account for the substantial morbidity and mortality in such patients. Walder et al. ${ }^{1}$, in 1971, were the first to identify this increased risk and publish their observations on a group of Australian renal-transplant recipients.

However, the available data pertaining to skin cancer risks in renal transplant recipients are inconsistent and much of it is derived from international studies and the number of studies with a defined control population is small.

\section{PATIENTS AND METHODS}

We performed a retrospective review of data collected contemporaneously on all patients undergoing renal transplantation at the University Hospital Olomouc Transplant Center between January 1984 and December
2009 who received a transplant follow-up at the study center. Patients having the skin cancer diagnosed before transplant were excluded from the study.

\section{Immunosuppression}

Given the long period of the study, the immunsuppressive regiments employed varied appreciably. In the period 1984-1998 triple therapy with cyclosporine, azathioprine, and prednisone was most commonly used. Since 1999, mycophenolat mofetil replaced azathioprine as the third agent. Tacrolimus was introduced in our centre in 1999, and has been occasionally used in place of cyclosporine. Antibody agents have been used as induction therapy in patients deemed to be at high immunologic risk, and for delayed graft function. Rejection episodes were initially treated with pulse methylprednisolone. Steroid-resistant, or severe rejection, episodes were treated with the monoclonal antibody OKT3 or polyclonal antithymocyte globulin (ATG). Monoclonal antibodies directed against the interleukin 2 receptor have also been used in some cases.

\section{Data collection and analysis}

Information for the study population was primarily obtained from a database maintained at the study center on all transplant patients. The date of diagnosis and type of cancer were recorded for patients diagnosed with cancer. The figures were compared with the data 
registered in the National Cancer Registry of the Czech Republic (NOR CR). This was done on the basis of a Data Transmission Contract between the University Hospital Olomouc and Institute of Health Information and Statistics of the Czech Republic (UZIS CR). In the case of missing data on the incidence of cancer in patients followed in the transplant registry data amendments were performed. General population data on the incidence of malignancy were obtained from the National Cancer Registry of the Czech Republic.

To estimate risk compared with the general population, standardized incidence ratios (SIR) were calculated for non-melanoma skin cancers (C44) based on observed compared with expected numbers generated by multiplying the person-years at risk by the appropriate sex-, age-, and calendar year-specific incidence rates obtained from publicly Available National Cancer Registry data (19802007). Calendar times were categorized in 10 year periods (80s, 90s, 00s). The 95\% confidence intervals were computed using assumption of Poisson-distributed observed number of cases. Data preparations and analyses were performed using STATA statistical software, version 10.1.

\section{RESULTS}

For the time-period considered, a total of 603 renal transplant recipients received a transplant follow-up at the University Hospital Olomouc Transplant Center. There were $368(61 \%)$ male and 235 (39\%) female recipients with a mean follow-up duration of 66 months (range, $0-141$ months). The mean age at time of transplantation was $47.7 \pm 12.8$ years. Overall, there were 101 patients with a diagnosis of malignancy detected.

\section{Non-melanoma skin cancer}

Six hundred subjects without a pretransplant history of skin cancer were enrolled in the study. The cohort produced a total of 4795.951 person-years at risk followup. In 52 patients (34 males, 18 females) a total of 124 non-melanoma skin tumours were identified, of which $76(61.2 \%)$ were basal cell carcinomas (BCC) and 48 (38.7\%) squamous cell carcinomas (SCC). The mean time between transplant and diagnosis was $62.4 \pm 38.4$ months. Pacients with NMSC appeared to be older at the time of transplant, with a mean age of $54.7 \pm 7.8$ years. The mean age at time of diagnosis of NMSC was $60.7 \pm 10,0$ years.

The majority of patients with NMSC received cyclosporine-based immunosuppressive therapy combined with azathioprine and prednisolone $(n=36)$. Mycophenolate mofetil was used with calcineurine inhibitors and prednisolone in 13 cases, and 3 patients had tacrolimus- based initial immunosuppression. Seven cases received antibody induction.

Using a $P$ value $<0.05$ as a cut-off, the SIR for all NMSC cancers was significant at 7.39 (CI 5.52-9.70) suggesting that overall risk for developing basal cell carcinoma or squamous cell in the renal transplant population is much higher than in the general Czech Caucasian population.

\section{Melanoma}

In our study, we revealed 2 patients with malignant melanoma (MM), which occurred 42 and 74 months after renal transplantation at patient ages 35 and 70 years, respectively. Both patients had triple therapy with cyclosporine, azathioprine, and prednisone. One of them received antithymocyte globulin (ATG) therapy.

The data correspond to a relative risk for developing this type of tumour of 2.52 (95\% CI 3.83-69.87) in comparison to the general population.

\section{Merkel cell carcinoma}

We experienced one patient with merkel cell tumour (MCC). He underwent renal transplant at the age of 55. The tumour appeared 46 months later. In his 59th year, a reddish-brown nodule sized 20x30 mm occurred on his right buttock. Although he received optimal therapy (radical excision, modification of immunosuppressive regiment - rapamycin instead of cyclosporine-based inicial therapy, and chemotherapy), he died due to tumour generalization 7 months after the diagnosis.

\section{Other skin tumours}

We have not seen any case of Kaposi's sarcoma, cutaneous lymphoma or malignant fibrous histiocytoma in a renal transplant recipient in our study cohort.

\section{DISCUSSION}

The literature suggests that the posttransplantation skin cancer incidence varies geographically, occurring with increased frequency in geographical latitudes associated with high ambient sun exposure ${ }^{2-10}$. The highest figures have been observed in the transplant population studies in Australia and New Zealand ${ }^{3,4}$.

Also studies analysing data of transplant recipients from Nordic countries showed considerably increased SIR for skin cancers. Kyllönen et al. ${ }^{5}$ presented SIR 39.22, 95\% CI 29.29-51.43 for skin cancer in a Finnish transplant population, Adami et al. showed marked excesses of nonmelanoma skin cancer transplant recipients in Sweden (SIR 56.2; 95\% CI 49.8-63.2) (ref. ${ }^{6}$ ). A similarly high incidence was demonstrated in Hartevelt's et al. ${ }^{7}$ study from The Netherlands.

Some extremely low skin cancer incidence in patients after transplantation have been referred by Japanese and Korean authors ${ }^{8,9}$. This may be due to the low freqency of NMSC in the local general population ${ }^{10}$.

However, meta-analysis on this issue performed by Grulich et al. showed SIR 28.6, 95\% CI 9.39-87.2 for $\mathrm{NMSC}^{11}$.

Consistent with the findings of most studies examining post-transplant malignancy, we found an increase in the risk for skin cancer, particularly non-melanoma skin cancer, in renal transplant recipients in comparison to the general population (SIR 7.39, 95\% CI 5.52-9.70 for NMSC).

In our study, the ratio of BCC/SCC was almost $3 / 2$, thus resembling the situation in the general population 
where $\mathrm{BCC}$ highly outnumbers $\mathrm{SCC}$ in a ratio of $\mathrm{BCC} /$ SCC of $4 / 1$. According to most publications, in the transplant population, the risk increases linearly for basal-cell carcinomas and exponentially for squamous-cell carcinomas, resulting in $\mathrm{SCC}$ as the the most common skin cancer type in renal transplant recipients ${ }^{12,13}$. However, in a Hispanic renal-transplant population followed up for the first 3 years after transplantation, $\mathrm{BCC}$ was diagnosed more often than $\mathrm{SCC}^{14}$. The reversal of SCC/BCC ratio is also less pronounced in Australia (1.5/1) (ref. $\left.{ }^{3}\right)$ and New Zealand (1.2/1) ( ref. $\left.^{15}\right)$.

It has been suggested that certain immunosuppressive medications, including cyclosporine and azathioprine, may have both mutagenic and immunosuppressive effects. Cyclosporine, through induction of transforming growth factor $\beta$, has been shown to induce the progression of murine skin cancers, and azathioprine may function as both a photosensitizer and a mutagen ${ }^{16-18}$. In our study cyclosporine and azathioprine were the most common immunosuppressants given to patients who developed skin cancers.

However, there is controversy over whether certain immunosuppressive medications are associated with a greater risk of skin cancer or whether it is the cumulative level of immunosuppression alone that determines the risk ${ }^{19}$.

Rapamycin is a newer immunosuppressive medication that may have antiproliferative effects ${ }^{20}$.

Increasing age at transplantation has been identified as significant risk factor for subsequent skin cancer development in a number of studies ${ }^{4,19}$.

In accordance with this, in our study the mean age at time of transplantation was $47.7 \pm 12.8$ years in all transplant recipients while patients who developed skin cancer were older at the time of transplant with a mean age of $55.6 \pm 10.2$.

We noted several cases of rarer occuring skin cancers, two case of maligant melanoma and one case of merkel cell carcinoma. We are aware that even with the long time span, the total number of cases is small which limits the statistical power. In the literature, the risk for MM occurence has been reported to be increased by a factor of 1.6 to 3.4 in Europe $\mathrm{e}^{21,22}$ and by a factor of 2 to 4 in Australia, compared with the risk in the general population $^{23}$. The reported mean interval between transplantation and the diagnosis of melanoma is five years ${ }^{24}$.

Merkel cell carcinoma (MCC), also known as cutaneous neuroendocrine carcinoma, is an uncommon tumour with an incidence of 0.4 per 100000 in the nonimmunosuppressed population. Fifty-five cases of MCC were reported in transplant recipients by Euvrard (2002) ( ref. $^{23}$ ). A more recent Finnish study reported 3 cases among 4200 individuals who had undergone renal transplantation from 1967 to 2005 (ref. ${ }^{25}$ ).

We have not seen any case of Kaposi's sarcoma in our series. However, the incidence of KS is reported as 400 to 500 times greater in transplant recipients than controls of the same ethnic origin ${ }^{26}$.

\section{CONCLUSION}

To our knowledge ours is the only Czech-based renal transplant program that has provided skin cancer risk estimates. Despite its limitations, due for the most part to its local nature, we believe that the findings are representative of the Czech renal transplant population, and highlight the need for increased vigilance for skin tumours in patients receiving renal transplantation.

It is important to advise patients before transplantation in regard to skin complications, provide regular dermatological follow-up, and tailor immunosuppressive regimens to minimum the doses to be compatible with good graft function.

\section{ACKNOWLEDGEMENTS}

We would like to acknowledge support of grant from Palacky University Olomouc (identification number 91110271). We would like to thank to Institute of Health Information and Statistics of the Czech Republic (UZIS CR).

\section{REFERENCES}

1. Walder B, Robertson M, Jeremy D. Skin cancer and immunosuppression. Lancet 1971;2:1282-3.

2. Bouwes-Bavinck JN, De Boer A, Vermeer BJ, Hartevelt MM, van der Woude FJ, Claas FH, et al. Sunlight, keratotic skin lesions and skin cancer in renal transplant recipients. Br J Dermatol 1993; 129:242-9.

3. Bouwes-Bavinck JN, Hardie DR, Green A, Cutmore S, MacNaught A, O'Sullivan B, et al. The risk of skin cancer in renal transplant recipients in Queensland, Australia: a follow-up study. Transplantation 1996; 61:715-21.

4. Ramsay H, Fryer A, Hawley C, Smith AG, Nicol DL, Harden PN. Non-melanoma skin cancer risk in the Queensland transplant population. Br J Dermatol 2002; 147: 950-6.

5. Kyllönen L, Salmela K, Pukkala E. Cancer incidence in kidneytransplanted population. Transpl Int 2000; 13:394-8.

6. Adami J, Gäbel H, Lindelö B, Ekströ K, Rydh1 B, Glimelius B. Cancer risk following organ transplantation: a nationwide cohort study in Sweden. Br J Cancer 2003; 89:1221-7.

7. Hartevelt MM, Bavinck JN, Kootte AM, Vermeer BJ, Vandenbroucke JP. Incidence of skin cancer after transplantation in The Netherlands. Transplantation 1990; 49:506-9.

8. Hoshida Y, Tsukuma H, Yasunaga Y, Xu N, Fujita MQ, Satoh T, Ichikawa Y, et al. Cancer risk after renal transplantation in Japan. Int J Cancer 1997; 71:517-20.

9. Ju MK, Joo DJ, Kim SJ, Huh KH, Kim MS, Jeon KO, et al. Chronologically different incidences of post-transplant malignancies in renal transplant recipients: single centrer experience. Transpl Int 2009; 22:644-53.

10. Parkin DM, Muir CS, Whelan SL, Gao YT, Ferlay J, Powell J. Cancer Incidence in Five Continents, Vol. VI, IARC Scientific Publication 120, IARC, Lyon 1992.

11. Grulich AE, van Leewen MT, Falster MO,Vajdic CM. Incidence of cancers in people with HIV/AIDS compared to immunosuppressed transplant recipients: a meta-analysis. Lancet 2007; 370:59-67.

12. Lindelöf B, Sigurgeirsson B, Gäbel H, Stern RS. Incidence of skin cancer in 5356 patients following organ transplantation. $\mathrm{Br} \mathrm{J}$ Dermatol 2000; 143:513-9.

13. Moloney FJ, Comber H, O'Lorcain P, O'Kelly P, Conlon PJ, Murphy GM. A population-based study of skin cancer incidence 
and prevalence in renal transplant recipients. Br J Dermatol 2006; 154:498-504.

14. Ferrandiz C, Fuente MJ, Ribera M, Bielsa I, Fernández MT, Lauzurica R, et al. Epidermal dysplasia and neoplasia in kidney transplant recipients. J Am Acad Dermatol 1995; 33:590-6.

15. Hepburn DJ, Divakar D, Bailey RR, Macdonald KJ. Cutaneous manifestations of renal transplantation in a New Zealand population. N Z Med J 1994; 107:497-9.

16. Hojo M, Morimoto T, Maluccio M, Asano T, Morimoto K, Lagman $\mathrm{M}$, et al. Cyclosporine induces cancer progression by a cell-autonomous mechanism. [see comments] Nature 1999; 397:530-4.

17. Moore DE, Sik RH, Bilski P, Chignell CF, Reszka KJ. Photochemical sensitization by azathioprine and its metabolites. Part 3 . A direct EPR and spin-trapping study of light-induced free radicals from 6-mercaptopurine and its oxidation products. Photochem Photobiol 1994; 60:574-81.

18. Kelly GE, Meikle W, Sheil AG. Effects of immunosuppressive therapy on the induction of skin tumors by ultraviolet irradiation in hairless mice. Transplantation 1987; 44:429-34.

19. Kovach BT, Stasko T. Skin cancer after transplantation. Transplantation Rev 2009; 23:178-189.
20. Guba M, von Breitenbuch P, Steinbauer M, Koehl G, Flegel S, Hornung M, et al. Rapamycin inhibits primary and metastatic tumor growth by antiangiogenesis: involvement of vascular endothelial growth factor. Nat Med 2002; 8:128-35.

21. Jensen P, Hansen S, Moller B, Leivestad T, Pfeffer P, Geiran O, et al. Skin cancer in kidney and heart transplant recipients and different long-term immunosuppressive therapy regimens. J Am Acad Dermatol 1999; 40:177-86.

22. Birkeland SA, Storm HH, Lamm LU, Barlow L, Blohme I, Forsberg $B$, et al. Cancer risk after renal transplantation in the Nordic countries 1964-1986. Int J Cancer 1995; 60:183-9.

23. Euvrard S, Kanitakis J, Claudy A. Neoplastic skin diseases in organ transplant recipients. Am J Cancer 2002; 1:109-20.

24. Penn I. Malignant melanoma in organ allograft recipients. Transplantation 1996; 61:274-8.

25. Koljonen V, Kukko H, Tukianen E, Böhling T, Sankila R, Pukkala $\mathrm{E}$, et al. Incidence of Merkel cell carcinoma in renal transplant recipients. Nephrol Dial Transplant 2009; 24:3231-5.

26. Penn I. Kaposi's sarcoma in transplant recipients. Transplantation 1997; 64:669-73. 